\title{
Reflexiones sobre una experiencia educativa para niñeces y juventudes rurales: el caso del proyecto "Desde las Raíces" de Caracol Psicosocial A.C.
}

David Sanchéz-Sanchéz ${ }^{1}$, (iD) Patricio Andrés Meza-Opazo², (iD) Claudia Paulina Águila-Robles ${ }^{3}$

${ }^{1}$ Universidad de Guadalajara. Caracol Psicosocial A.C. Departamento de Desarrollo Social. Prol. Parres Arias no. 150, San José del Bajío, Zapopan, Jal. México. ${ }^{2}$ Caracol Psicosocial A.C. ${ }^{3}$ Colegio Luis Silva A.C.

Autor para correspondência/Author for correspondence: mpsdavids@gmail.com

RESUMEN. El presente artículo tiene como objetivo hacer un recorrido por la experiencia en el trabajo desarrollado entre 2011 y 2017 con niñeces y juventudes dentro del Proyecto "Desde las Raíces" de la asociación civil Caracol Psicosocial, ubicada en la comunidad de Palos Altos en el municipio de Ixtlahuacán del Río en el estado de Jalisco, México, y los impactos posteriores que esta ha tenido de forma directa en sus vidas. Para estos fines, se hablará de los orígenes del proyecto educativo, los aportes teóricos que lo nutren y alimentan, las acciones emprendidas a lo largo del tiempo, además de algunos relatos que narran los impactos en las trayectorias biográficas de los participantes $\mathrm{y}$, por último, una reflexión sobre lo que ha significado para los autores del presente texto el formar parte de este proyecto.

Palabras clave: juventudes rurales, psicología social, educación ambiental. 


\title{
Reflections on an educational experience for rural children and youth: the case of the project "From the Roots" of Caracol Psychosocial A.C.
}

\begin{abstract}
The purpose of this article is to review the experience of the work developed between 2011 and 2017 with children and youth within the "From the Roots" Project of the civil association Caracol Psicosocial, located in the community of Palos Altos in the municipality of Ixtlahuacán del Río in the state of Jalisco, Mexico, and the subsequent impacts it has had directly on their lives. For these purposes, we will discuss the origins of the educational project, the theoretical contributions that nurture and feed it, the actions undertaken over time, in addition to some stories that narrate the impacts on the biographical trajectories of the participants and, finally, a reflection on what it has meant for the authors of this text to be part of this project.
\end{abstract}

Keywords: rural youth, social psychology, environmental education. 


\section{Reflexões sobre uma experiência educativa para crianças e jovens rurais: o caso do projeto "Desde as Raízes" de Caracol Psicossocial A.C.}

RESUMO. Este artigo visa relatar a experiência no trabalho desenvolvido entre 2011 e 2017 com crianças e jovens no âmbito do Projeto "Desde as Raízes" da associação civil Caracol Psicossocial, localizada na comunidade de Palos Altos, no município de Ixtlahuacán del Río, no estado de Jalisco, México, e os impactos subsequentes que este tem tido diretamente nas suas vidas. Para estes fins, falaremos sobre as origens do projeto educativo, as contribuições teóricas que o alimentam, as ações empreendidas ao longo do tempo, bem como algumas histórias que narram os impactos nas trajetórias biográficas dos participantes e, finalmente, uma reflexão sobre o que significou para os autores deste texto fazerem parte deste projeto.

Palavras-chave: juventude rural, psicologia social, educação ambiental. 


\section{Introducción}

"La educación problematizadora se hace, así, un esfuerzo permanente a través del cual los [humanos] van percibiendo, críticamente, cómo están siendo en el mundo el que y con el que están".

Paulo Freire

Paulatinamente, las experiencias de educación alterna en el campo aumentan en número. Desde hace décadas se ha hablado de la necesidad de realizar procesos educativos que incorporen aspectos de la vida cotidiana, que cuestionen y miren críticamente la realidad y conduzcan a transformaciones y cambios sociales concretos sobre ella (Freire, 1987); siendo las problemáticas ambientales uno de los temas que ha tomado más interés ante las crisis socioambientales que se viven en general, $\mathrm{y}$ particularmente en muchos territorios latinoamericanos.

Muchas de esas experiencias y sus ricas aportaciones resultan poco conocidas pues sus gestores muchas veces no tienen la posibilidad de llevarlas hacia un proceso de publicación y difusión de lo vivido. En ese sentido este artículo pretende recuperar y presentar las reflexiones a partir de un proyecto específico dentro de la trayectoria de una organización, que surge en el medio rural para generar una reapropiación de la psicología que se traduzca en formas de trabajar más adecuadas para los contextos campesinos. Lo cual resulta relevante pues la psicología, como muchas otras disciplinas profesionales enseñadas en las universidades tienen un sesgo urbanocéntrico que muchas veces dificulta o hace poco eficaces las intervenciones por no ser sensible a las realidades socioculturales de los espacios rurales.

Particularmente el contexto rural de esta experiencia es la localidad de Palos Altos, en el municipio Ixtlahuacán del Río; una comunidad rural de aproximadamente 1200 habitantes, cuya actividad económica principal es la agricultura y el comercio local, organizados en torno al monocultivo de maíz; fuertemente influenciada por dinámicas migratorias a Estados Unidos; con rasgos culturales de las llamadas sociedades rancheras (Ávila \& Velázquez, 2006), las cuales están caracterizadas por una organización familiar patriarcal y conservadora, ligadas a una identidad cercana a la charrería, la productividad agrícola y la religiosidad católica.

Para dar cuenta de una manera ordenada de esta experiencia, el artículo está organizado de la siguiente manera: Se inicia recuperando los orígenes del proyecto analizado, como parte del trabajo de una asociación civil. Luego se mencionan algunos elementos teóricos que estuvieron presentes en toda la acción 
realizada, relacionados principalmente con la psicología, y brevemente se cruzan elementos de educación popular, posdesarrollo y estudios de juventudes. Posteriormente se recuperan las diferentes acciones realizadas con el proyecto a manera de síntesis que permita ver el proceso en sus distintas etapas. Después, partiendo de una sistematización del mismo realizada en 2017, se presentan algunos discursos de las y los participantes de la experiencia para ejemplificar los efectos e impactos que ha llegado a tener entre quienes formaron parte del proyecto. Finalmente, se presentan algunas reflexiones que aportan a la discusión de la psicología rural, desde los procesos educativos con niñeces y juventudes rurales.

\section{Los orígenes del proyecto: el trabajo de Caracol Psicosocial}

En la comunidad de Palos Altos se encuentra Caracol Psicosocial, una asociación civil fundada en 2009 por un grupo de psicólogos que aspiraban a intervenir en la transformación de las problemáticas de comunidades de la región formada por los municipios de Ixtlahuacán del Río y Cuquío realizando trabajo comunitario desde una perspectiva psicosocial. Se buscó generar proyectos que pudieran ser financiados por entidades públicas y privadas, con la expectativa de que estos fueran una alternativa laboral ante el panorama de desempleo al que se enfrentaban como jóvenes egresados de la universidad. Sin embargo, durante cinco años de trabajo en esa lógica, solo se consiguió financiamiento público para cuatro proyectos concretos en cuatro comunidades distintas, sobre temáticas de género, cultura y medio ambiente. Gracias a esto la asociación civil pudo precariamente sostener su trabajo e identidad y empleó a tres jóvenes por cortos periodos de tiempo. A la par, se fueron realizando otros proyectos no financiados, con lo que se fue se acumulando experiencia sobre la región y sobre los laberintos institucionales para sobrevivir con escasos fondos económicos, pero avanzando en una lógica comunitaria y autogestiva.

Formalmente la asociación se ha planteado como misión "Promover, crear y acompañar procesos psicosociales en la comunidad de Palos Altos, que aspiren a la construcción de alternativas autogestivas frente a sus necesidades educativas, ambientales $y$ socioculturales"; esto con la visión de "Contribuir a la transformación social de Palos Altos a través de espacios autogestivos de aprendizajes $y$ 
participación social que posibiliten una vida comunitaria digna."

Sus áreas de trabajo, por otro lado, son: la Construcción de Autonomía; Sensibilización $\quad$ y $\quad$ Educación; Documentación e Investigación; Proyectos Colectivos: Consultoría Psicosocial y terapéutica.

Como proyecto social ha estado vinculado e influenciado por movimientos y luchas sociales del país; en específico con los Municipios Autónomos Rebeldes Zapatistas, bases de apoyo del EZLN en el estado de Chiapas; con la Red en Defensa del Maíz y con la Asamblea Nacional de Afectados Ambientales. Estos movimientos sociales han repercutido en sus planteamientos y modos de acción; orientándose a un pensamiento crítico y situado territorialmente (Osorio, 2016).

Dos años después de la fundación del Caracol Psicosocial surge el proyecto "Desde las Raíces", con el objeto de realizar una educación ambiental situada, más enfocada en el contexto real de niños, niñas y jóvenes de Palos Altos, como alternativa a la manera tradicional $\mathrm{y}$ descontextualizada que se realizaba en la escuela. Con dicho proyecto, el sentido de la organización se reorienta, como se mostrará más adelante, dando lugar a un trabajo más coherente con la comunidad, y abriendo el campo de reflexión teórica sobre juventudes rurales (Sánchez, 2020).

Actualmente, la asociación de Caracol Psicosocial cuenta con un espacio físico donde se tiene una huerta orgánica y sustentable, se siguen documentando las problemáticas ambientales de la zona en relación a la agroindustria, y se encuentra en reestructuración de sus fundamentos teóricos y prácticos, para proponer una nueva forma de trabajo con niñeces $y$ juventudes rurales que integre toda la experiencia y las reflexiones de los años pasados, buscando integrar las perspectivas psicosocial, territorial, agroecológica y de género en un nuevo proyecto.

\section{Reflexiones teóricas que confluyeron en el proyecto}

La acción siempre surge de un conjunto de ideas o de teorías que le dan sentido, en ese sentido se vuelve praxis, ya que de los procesos de reflexión-acción se siguen reelaborando o contrastando con nuevos referentes teóricos que enriquecen el conjunto y desdibujan la dicotomía teoría-práctica en constante reflexividad. Particularmente, el trabajo realizado por Caracol Psicosocial en el proyecto "Desde las raíces" no puede identificarse con una sola línea de pensamiento, sino que es 
preciso mirar hacia diversos marcos teóricos para comprenderlo.

Cabe destacar que la perspectiva psicosocial, que no considera lo individual y lo social como entidades separadas sino como una misma cosa, es la lente y el espejo con la que la teoría y la práctica son vistos. Sin embargo, aunque la psicología social ha sido útil para guiar y reflexionar sobre la investigación, la intervención y la práctica sociales que se llevaron a cabo durante los años del proyecto; además de estos referentes se intersectaron, con otros como la educación popular y ambiental, el posdesarrollo y los estudios de juventudes. Como se muestra a continuación.

\section{Psicologías Sociales Latinoamericanas}

Dentro de las Psicologías Sociales Latinoamericanas se reconocen fundamentalmente a la psicología de la liberación, la comunitaria, la colectiva y la rural; que surgen en América Latina en contraposición a la psicología hegemónica desarrollada en Norteamérica y Europa que responde a contextos y necesidades específicas (muchas veces relacionadas con un poder opresivo) y que se enseñan en las facultades latinoamericanas de psicología como conocimientos avanzados y "verdaderos", los cuales al llevarse a la praxis se vuelven descontextualizados $y$ divorciados de las realidades de los pueblos.

A su vez, la psicología social de la liberación fundada por el jesuita Ignacio Martín-Baró, plantea que el psicólogo puede desde la especificidad de su disciplina tomar en cuenta las problemáticas que están relacionadas a lo sociológico y o económico y aportar elementos para enfrentarlas; en lugar de dejarlas de lado por considerar que "no entran" en su campo de acción. Para lograrlo, es preciso que se libere a la psicología de sí misma, es decir, utilizar críticamente sus ideas y modelos. Es preciso pues, buscar un mayor conocimiento de las realidades sociales de y junto con los pueblos, su transformación y liberación; reflexionar y teorizar sobre este proceso y; contar con saberes teóricos, metodológicos y epistemológicos de la psicología para poder dialogar entre estos dos ámbitos y ofrecer una síntesis de ambos.

La psicología comunitaria surge inspirándose en algunos aportes de la Psicología de la Liberación y tiene como a una de sus máximas exponentes a Maritza Montero. La psicología social comunitaria latinoamericana, a entender de una experiencia boliviana "se dedica a la organización de esfuerzos colectivos de sectores marginados y excluidos de la 
sociedad, dirigidos a superar su situación a través del cambio social" (Mendoza, 2008, p.36), así como a estudiar científicamente los fenómenos sociales que ocurren en ese proceso.

De la psicología social comunitaria se rescata la compresión de la comunidad como una entidad independiente de quien investiga o interviene; en la que el grupo de personas que la conforma se encuentra en un proceso dialéctico y cambiante (Montero, 1980) por lo tanto, tiene que asumirse de manera explícita que la comunidad cuenta con una historia, una organización, unos intereses y necesidades propias que preceden al proceso de investigación/intervención. De esta manera las acciones de tipo paternalistas o autoritarias quedarían rechazadas debido a que niegan la autonomía y la independencia de las comunidades. La intención de un proyecto planteado desde la psicología comunitaria buscaría, en cambio, fomentar o fortalecer procesos autogestivos, autónomos y de toma de conciencia (Montero, 1984).

En general el método que sigue la psicología comunitaria para desarrollar sus intervenciones tiene algunos pasos principales, los cuales van acompañados de un proceso mayor de problematización (Montero, 2006)

1. Familiarización con la comunidad.
2. Identificación de necesidades (realizada junto con la comunidad)

3. Reunión con líderes y miembros de la comunidad. Establecimiento de metas específicas de corto y largo plazo. División de tareas para lograrlas

4. Trabajo colectivo

5. Establecimiento y consecución de metas específicas a corto y largo plazo

Desde la Psicología Colectiva (1994, 2001), por otro lado, se aporta una mirada más integral de lo psicosocial y para Fernández Christlieb esta consiste en:

la comprensión (y narración) de los procesos (y contenidos) de construcción (y destrucción) de símbolos (y significados) con los que una colectividad concuerda su realidad, es decir, descubrir qué pensamientos y sentimientos ocurren a una sociedad en un momento y lugar determinados, y de dónde, por qué, cómo, cuándo, para qué, y quién o qué los piensa y siente. (Fernández Christlieb, 1994, p. 293).

A partir de esto se puede decir que al psicólogo colectivo le competería comprender y realizar una buena interpretación de la comunidad para crear nuevos sentidos. Para esta forma de concebir la psicología social se toma su énfasis en la construcción de la intersubjetividad a través de símbolos, significados y sentidos generados en la 
vida cotidiana, en espacios determinados que contienen a personas específicas. Además, hace énfasis en el carácter afectivo de la realidad social, para lo cual se necesita reinterpretarla constantemente.

Otro de los referentes latinoamericanos de la psicología que ha nutrido el proyecto es la apuesta por la construcción de una Psicología rural, lo cual implica más que llevar la psicología tradicional al campo, sino precisamente la generación de una teoría y una práctica que resulte apropiada para las poblaciones rurales y sus problemáticas. Fernando Landini avanza en ese sentido en su tesis doctoral "Psicología en el ámbito rural, subjetividad campesina y estrategias de desarrollo (2009)"; $\quad$ reconociendo los factores 0 procesos psicosociales vinculados con proyectos de desarrollo destinados a población campesina. Mientras que en otra obra colectiva, se menciona que la psicología rural es un campo de problemas que articulan psicología y ruralidad, entendiéndose como

un conjunto de temas, problemas o hechos para los cuales resulta relevante considerar tanto su dimensión rural como su dimensión psicológica o psicosocial, ya que sin la consideración de una de ellas nuestra posibilidad de comprensión y/o intervención se vería limitada en aspectos relevantes (Landini, 2015. p. 31).
De esta manera, la psicología rural, más que una disciplina bien definida es una apuesta por un modo de reflexionar, investigar y accionar, que contemple la dimensión psicosocial en los ambientes rurales en que se trabaja, reconociendo el sesgo urbanocéntrico de la psicología como se mencionaba antes.

\section{Educación popular entre lo ambiental y la pedagogía de la integralidad}

Hablar de educación popular remite a Paulo Freire. Para él la educación consiste en un diálogo entre educandos $\mathrm{y}$ educadores que permite la lectura crítica de la realidad para lograr su transformación. La educación así vista tiene fines políticos de cambio social e incorpora diversos aspectos de la vida del educando: valores, deseos, emociones, voluntad, cuerpo y conciencia. Jamás se limita a un ejercicio intelectual, sino que se mira desde su integralidad (Gutiérrez, 2011).

Cada uno de los participantes del acto educativo ejerce el rol de educador y aprendiz, al mismo tiempo, ya que considera que ambos aprenden los unos de los otros y no se trata de un proceso unidireccional. Freire invita a no permanecer neutral o indiferente ante las injusticias que ocurren el mundo, a tener un compromiso ético por la construcción de uno mejor. Incluso considera que es 
imposible no tener una postura política toda vez que el permanecer indiferente o al margen, lo que se está haciendo es legitimar el orden social existente. Así, de acuerdo a Alfonso Torres (2007), es preciso politizar la educación y pedagogizar la política, por lo que los rasgos distintivos de la educación popular serían: la lectura crítica de la realidad, una opción ético-política emancipadora, la contribución a la transformación de los sectores populares en protagonistas del cambio social, la educación como formación de conciencia crítica y metodologías de trabajo basadas en la construcción colectiva del conocimiento.

En estos procesos de educación popular, uno de los ámbitos que más se ha trabajado, por la creciente crisis ecológica son los procesos de educación ambiental, que es un tema que ha generado creciente interés sobre todo en las nuevas generaciones. Se trata de una racionalidad ambiental (Leff, 2004), que poco a poco se va constituyendo en una afectividad ambiental (Giraldo y Toro, 2020). La perspectiva ambiental nos orilla a entender la complejidad de la vida.

En este sentido los proyectos educativos tendrían que reconocerse parte de esa red, y apostar a la integralidad, es decir, entender la vinculación holística entre la sustentabilidad planetaria, las sociedades sustentables, $\quad$ y la sustentabilidad interior (Gutiérrez, 2011), visión que por demás está relacionada con una perspectiva psicosocial.

\section{Postdesarrollo y epistemologías del sur}

Si bien el trabajo realizado no es una solución a toda la complicada y compleja gama de problemáticas que se enfrenta como sociedad y que se prevén para las juventudes y niñeces; es verdad que aporta a la comprensión global de las mismas y en esto nos apoya la veta reflexiva de Boaventura de Sousa Santos sobre la "Epistemología del Sur", entendida como

la búsqueda de conocimientos $\mathrm{y}$ criterios de validez del conocimiento que otorguen visibilidad $y$ credibilicen las prácticas cognitivas de las clases, de los pueblos, y de los grupos sociales que han sido históricamente victimizados, explotados y oprimidos por el colonialismo y capitalismo globales (Santos, 2009)

Esta epistemología apunta sus reflexiones fundamentalmente a las prácticas de conocimiento que permitan intensificar la voluntad de transformación social. En ese sentido, a partir de la experiencia con juventudes y niñeces rurales, en sus intentos de transformación de la realidad socioambiental que se encontraban, surgió una crítica al modelo de desarrollo hegemónico, que se 
materializaba en el cuestionamiento al monocultivo de maíz como origen de graves problemáticas para las y los jóvenes. Esta crítica coincide con el posdesarrollo (Escobar, 2005, 2007), en tanto que nos invita a reconocer como han operado los modelos de desarrollo en las comunidades y cuales han sido sus efectos más allá de lo socioeconómico; lo cual concuerda en parte con lo que se propone la psicología rural como campo problemático de estudio y acción.

\section{Juventudes rurales}

En las discusiones teóricas, lo juvenil es considerado más allá de una etapa diferenciada del ciclo vital, sino como una condición que requiere herramientas analíticas para comprender sus distintas expresiones (Reguillo, 2010), pues estas son una muestra de las transformaciones de las sociedades. Es necesario pues entender la juventud desde una forma más sociocultural que cambia de forma y de contenido a través del tiempo y del espacio (Urteaga, 2011).

Sin embargo, los estudios de juventudes y en general las políticas públicas dirigidas a jóvenes tienen un sesgo urbanocéntrico (Kessler, 2007), en general las juventudes rurales han sido invisibilizadas, a pesar de que muchos autores les consideren como posibles protagonistas del desarrollo rural (Durston, 2001).

$\mathrm{Al}$ abordar las juventudes rurales, se abre un panorama complejo y poco estudiado teóricamente. Incluso inspirada por esta experiencia surge una propuesta teórica que es la condición juvenil rural (Sánchez, 2020), donde se propone que lo estructural, lo territorial y lo intersubjetivo son dimensiones centrales para la comprensión de estas juventudes.

Además en el trabajo con este sector de la población es necesario entender que "los modos de acceder a la participación en sus territorios por parte de las y los jóvenes, se estructuran desde la perspectiva de ganar espacios y de resistir a las prácticas adultocéntricas de las y los mayores" (Duarte K., 2013, p. 182). Esto implica una apuesta por acompañar los procesos juveniles desde una perspectiva comunitaria, de vigilancia constante al adultocentrismo, pero entendiendo que la relación con jóvenes es vital para los procesos de educación ambiental y de defensa territorial.

\section{Una síntesis del Proyecto "Desde las raíces"}

“Desde las raíces", ha sido uno de los procesos más importante generado por Caracol en la comunidad de Palos Altos. Inició a mediados de 2011, de uno de los 
proyectos financiados que logró la asociación. Se partió de una metodología de psicología social comunitaria con un planteamiento de educación ambiental situada en la comunidad, más cercano al ecologismo y fue constituyéndose en una perspectiva psicosocial crítica al desarrollo y con una visión de las problemáticas de las juventudes e infancias rurales, buscando una perspectiva de la integralidad.

El proyecto inició con un diagnóstico de la percepción ambiental en niños, niñas y adolescentes de la comunidad. Entendiendo la percepción ambiental como un proceso social de asignación de significados a los elementos del entorno natural y a sus cursos de transformación y/o deterioro (Barraza, 1998, Maneja et. al 2009). El estudio fue realizado en las tres escuelas de la localidad, a través de dibujos y cuestionarios se sondeó la forma como las niñeces y juventudes miran el medio ambiente y sus problemas.

Después, se realizaron una serie de módulos formativos a través de talleres de educación ambiental para promover el involucramiento de jóvenes de trece a dieciocho años en las problemáticas de la comunidad de Palos Altos. Dichos talleres, se realizaron de manera semanal durante el 2012, y tenían por objetivo generar un proceso formativo situado en la realidad social y ambiental de la comunidad. Algunos de los temas tratados fueron manejo de residuos, consumo responsable y cuidado del agua y del monte, cambio climático, manejo de suelos y ecotecnologías. Con una metodología pedagógica que buscaba unir los temas ambientales con las realidades concretas de la localidad, además se contemplaba una excursión a un sitio significativo relativo al problema ambiental tratado, esto sumado acciones de intervención comunitaria guiadas por los jóvenes; además se buscaba conformar un espacio de socialización juvenil y convivencia afectiva en cada una de las reuniones.

Terminado el financiamiento del proyecto, se termina de conformar el Colectivo Juxmapa (Jóvenes Unidos por el Medio Ambiente de Palos Altos) y con ellas y ellos (catorce en total) se decidió seguir el proceso de manera autónoma y autogestionado, realizando actividades en la comunidad y reuniones de reflexión, formación y diagnóstico del contexto; además de constituirse en un espacio de socialización para las y los jóvenes, quienes han tenido la oportunidad de contar como una alternativa a la escuela para reconocerse como compañeros. 
Ilustración 1 - Logotipo diseñado por jóvenes de Palos Altos pertenecientes al colectivo Juxmapa.

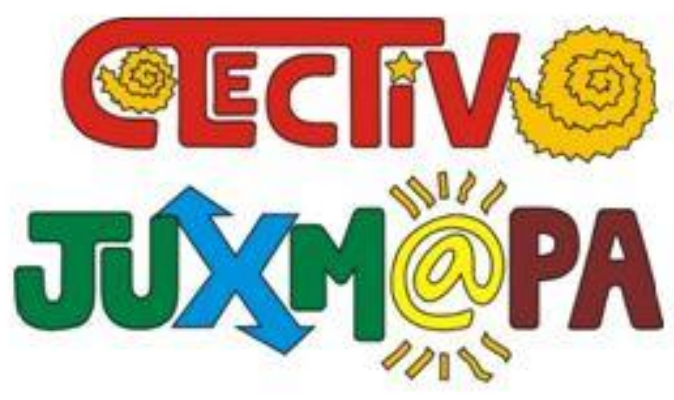

Fuente: Documentos básicos de la organización.

El Colectivo Juxmapa se vincula también de manera activa con el proceso generado a partir del Tribunal Permanente de los Pueblos (TPP) donde los jóvenes se presentan para efectuar diversas demandas, por ejemplo: que el maíz deje de ser controlado por las empresas, que sean retiradas todas las imágenes de publicidad de los agrotóxicos y que estos dejen de utilizarse, que sean implementados proyectos de recuperación del suelo y la biodiversidad y que en las escuelas se pueda aprender de manera especial sobre la subsistencia digna en el campo en las condiciones actuales de devastación (GRAIN, 2014).

Desde esta experiencia de vinculación con el Tribunal, el Colectivo Juxmapa y Caracol Psicosocial, comienzan una profunda discusión, sobre la situación de las juventudes en el campo; contrastándola con la situación de las y los jóvenes de la ciudad. Integrándose posteriormente al movimiento "Jóvenes
Ante el Desastre y la Emergencia Nacional" formado principalmente por universitarios de distintas ciudades del país; quienes buscan visibilizar la situación actual del país y cómo afecta particularmente a la población joven; y que se sintieron reflejados en los planteamientos del colectivo y el análisis previo a los problemas de muchos jóvenes en la ciudad, es decir, se voltea a ver los lugares de los cuales son expulsados esos jóvenes con falsas promesas de desarrollo que provocan aún más vulnerabilidad de la que se tiene en el lugar de origen.

Durante este tiempo, se trabajó en reconocer las problemáticas ambientales y sociales relacionadas con el actual modo de producción agrícola, herencia de la revolución verde, impuesta a la generación de abuelos y padres de las y los jóvenes del colectivo y del país; caracterizado por privilegiar el monocultivo con semillas híbridas producidas por empresas transnacionales que también elaboran los 
agrotóxicos. Por la metodología de educación popular del proyecto, se ha puesto en tela de juicio el sistema educativo y sus efectos negativos en la juventud campesina y en general. Se han cuestionado las deficiencias de las escuelas de la comunidad, reconociendo que estas no propician la comprensión de los problemas que se viven, mucho menos para buscar alternativas. La única opción que se valora es ascender en el sistema de educación escolarizada, con la promesa de tener un mejor empleo lejos del campo, ante lo cual se comienza a plantear desde el colectivo una demanda muy clara: "Queremos vivir dignamente en el campo, cubriendo nuestras necesidades de subsistencia y recreación personal y comunitaria, ${ }^{\text {,ii }}$.

Por todo este proceso a raíz del Colectivo Juxmapa; Caracol psicosocial, que intervenía en cuatro localidades, decide centrar el trabajo sólo en la comunidad de Palos Altos. Esta decisión marca un giro importante para definirse como algo más que una organización legalmente constituida que depende de financiamientos externos y plantearse como un proyecto social de largo aliento que sobrepasa y cuestiona la tendencia de institucionalización de organizaciones sociales y ONGs; situado en un territorio específico, con problemáticas particulares a la vez que globales; es también una mirada particular cada vez más integral sobre la región y sus problemáticas; y un planteamiento distinto de trabajo comunitario, que apuesta a la acción desde el propio lugar de origen y la vida cotidiana, cuestionando con esto algunos de los efectos del trabajo comunitario en la visión modernista de intervención con el otro vulnerable desde la posición del experto social.

Se pretende con esto avanzar a una mayor integralidad y coherencia de los planteamientos y las acciones, pasando de un proyecto de educación ambiental a un posicionamiento juvenil crítico frente a las lógicas de destrucción de la territorialidad, la subsistencia y la vida digna de las comunidades rurales en México; encubiertas como problemas de desarrollo a corregirse con el tiempo y la profundización de los mismos modelos socioeconómicos (GRAIN, 2014).

De esta manera Caracol Psicosocial, que había iniciado como una particular solución al conflicto de salir de la comunidad para estudiar y volver a ella a buscar opciones de trabajo (en el caso de uno de los miembros fundadores); se convirtió, con el empuje del Colectivo Juxmapa, en un planteamiento que comienza a cuestionar los efectos del desarrollo en la región; generando una 
visión más socioterritorial (Svampa, 2019), que es fortalecido por más jóvenes del lugar que se sienten identificados y se apropian del proceso. En los últimos años se han ido generando elementos para plantear algunas de las situaciones más apremiantes para las nuevas generaciones del campo; hasta el punto que algunas organizaciones y movimientos nacionales (Red en Defensa del Maíz, Ejido San Isidro, Tribunal Permanente de los Pueblos, Asamblea Nacional de Afectados Ambientales, y Jóvenes ante la Emergencia Nacional) han llegado a considerar a las y los jóvenes del colectivo como interlocutores y aliados en procesos de lucha.

Las y los jóvenes que siguieron en el proceso, se apropiaron de la idea del proyecto "Desde las raíces", de realizar acciones comunitarias de promoción ambiental. Después de varias actividades, se reflexiona que trabajar con niños y niñas es pertinente, pues los procesos que aquellos vivieron en la conformación del Colectivo Juxmapa, se vieron varias veces entorpecidos, por los efectos de la educación formal descontextualizada. Por ejemplo, mientras que el colectivo cuestionaba el monocultivo y los agrotóxicos como el principal problema ambiental de la comunidad, la escuela secundaria seguía reproduciendo contenidos de educación ambiental ajenos a lo que se vive en el territorio; y sobre todo mientras en el colectivo se formaba un ambiente propositivo y proactivo, la escuela como institución fomentaba el conformismo y la obediencia; que genera actitudes apáticas en los jóvenes.

En una de las reuniones a inicios de 2014, uno de los jóvenes dijo que "si desde más chiquitos comienzan a pensar y a actuar diferente; entonces se van a animar a hacer más cosas en la comunidad". Un par de meses después, se hizo una actividad con niños y niñas. El impacto fue tal que uno de los niños, estuvo insistiendo que se abriera un grupo para los pequeños como el que existía para los jóvenes, y de su proactividad surgió el grupo infantil CARACOL (Compitas Aprendiendo a Regenerar la Agricultura la Comunidad y la Libertad), que comenzó a desarrollarse a partir de mayo de 2014; con catorce niños y niñas de diez a doce años, que se reunieron semanalmente durante dos años. 
Ilustración 2 - Niñas y niños del grupo infantil CARACOL facilitado por jóvenes del Colectivo Juxmapa y Caracol Psicosocial.

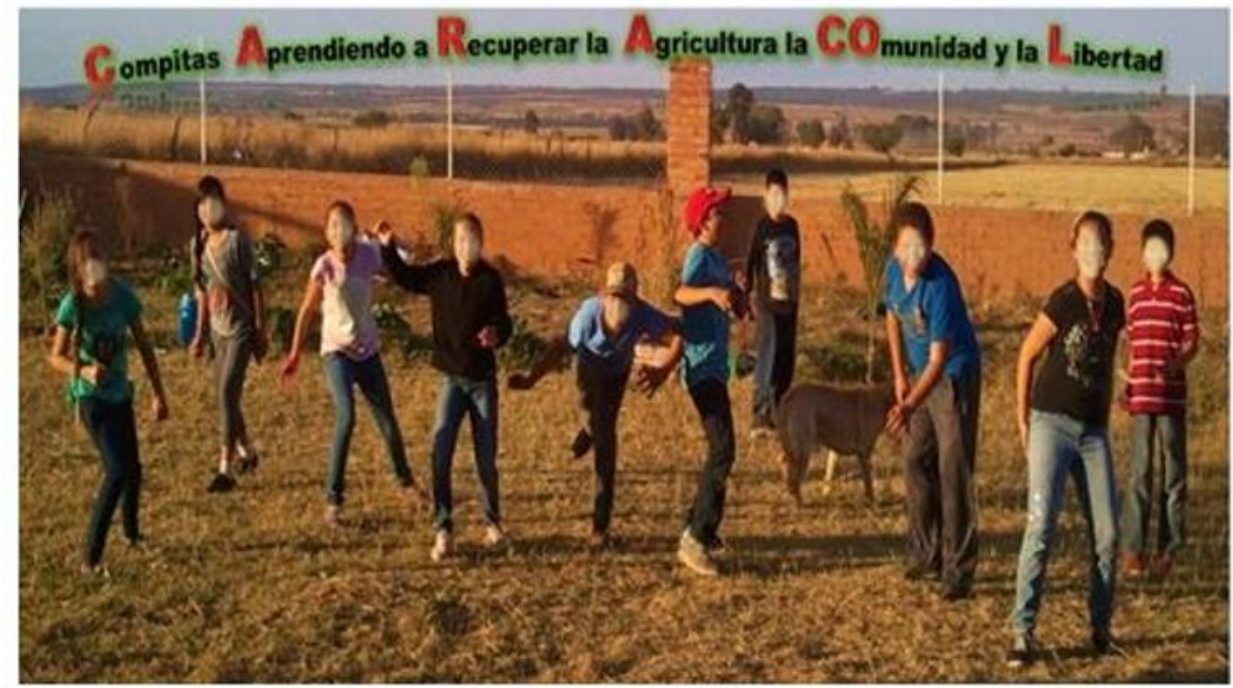

Fuente: Página de Facebook de Caracol Psicosocial A.C.

El grupo se centró en brindar a niños y niñas de la comunidad un espacio de convivencia y de formación, en torno a la siembra colectiva de una cama de cultivo, así como de pequeñas porciones de tierra individual delimitadas por neumáticos reciclados, en la que cada integrante podía sembrar lo que decidiera. Con el pretexto de la siembra se realizaban actividades educativas y juegos didácticos, que coordinaban los mismos jóvenes del Colectivo Juxmapa.

Detallando más los aprendizajes del proceso con las niñeces, se dividía en los tres componentes que se relatan en el título del grupo. La perspectiva de la regeneración se toma de los planteamientos agroecológicos como una tarea que se aplica no solo a la cuestión agrícola sino también como un proceso complejo, de orden incluso afectivo como recientemente se plantean algunos autores (Giraldo y Toro, 2020).

Cuando se habla de regenerar la agricultura se trabajaron aspectos como, reconectar con la tierra, reconocer el suelo, aprender a compostear, aprender a sembrar (colectivo-individual). El objetivo pedagógico de este componente iba relacionado a conectar a los/as niños/as con los procesos agrícolas y mostrar la alternativa de la agroecología en confrontación con el monocultivo de maíz que les rodea.

Cuando se abordó la regeneración de la comunidad, los tópicos trabajados fueron aprender a estar junt*s, a cooperar, a ser equipo, a proponer, a disponerse para las actividades. Estos puntos iban destinados a procurar una conciencia de 
participación comunitaria través del trabajo grupal, generando habilidades de convivencia colectiva y apuntando hacia la promoción de la autogestión (Ceballos y Tovar, 2010).

La regeneración de la libertad, aludía a aspectos más afectivos e internos y se planteaba desde los ejes que se mencionan a continuación: Aprender a conocernos, aprender a expresarnos, aprender a hacernos responsables. En este sentido se aludía a la necesidad de una educación emocional, necesaria tanto para el bienestar personal como para la integración a un grupo.

Todos estos aspectos se entretejían en la interacción que se daba entre niños niñas y jóvenes que vivían la experiencia y la intención era cercana a una pedagogía de la integralidad (Gutiérrez, 2011), como se mencionó antes. Con una metodología flexible que integraba aspectos ambientales, emocionales, grupales, lúdicos y reflexivos en cada una de las sesiones, vinculándolo con actividades relacionadas a la siembra de la huerta colectiva e individual.

Durante este proceso, se consolidó el Colectivo Juxmapa, con cinco miembros, que durante año y medio sostienen el trabajo con niños/as siendo facilitadores de las sesiones. Al realizarlo, se fueron haciendo más integrales y con más sentido los planteamientos del proyecto "Desde las raíces"; título que hacía referencia a la necesidad de trabajar con los más pequeños, apelando al sentido de responsabilidad que se genera cuando cuidas y acompañas a alguien más. De esta manera, así como el Caracol Psicosocial se transforma al entrar en diálogo con las y los jóvenes de Palos Altos; las y los jóvenes como colectivo se transforman al dialogar con las realidades de la niñez de la misma comunidad; esta experiencia, sumada a la interacción con adultos en los diferentes espacios de defensa territorial en que el colectivo comenzaba a participar, posicionaron la importancia de trabajar desde un enfoque intergeneracional (Escobar C, 2020).

La actividad del grupo de niñas/os CARACOL dejó de realizarse en 2016, y Colectivo Juxmapa terminó por disolverse en 2017. La razón de esto tuvo que ver con el mismo ciclo vital de los jóvenes, varios de los cuales se fueron a estudiar o a trabajar a otros lugares lejos de la comunidad. Cada uno de los y las jóvenes que estuvieron más cercanos siguen realizando algunas actividades sociales relacionadas con el proyecto, es evidente que el proyecto impactó en sus cursos de vida y les dio nuevas perspectivas incluso para migrar y establecerse en otros lugares y desde otros imaginarios. 
Una mirada a la experiencia desde las voces de sus participantes

En el año 2017 se organiza una reunión en Caracol con el objetivo de conocer los aprendizajes y vivencias de los jóvenes y niños/as trabajando "Desde las raíces" a manera de sistematización del proyecto; en la cual se pidió a los participantes que determinaran los momentos, conceptos y eventos más importantes a lo largo del proceso. A continuación, se hace un recuento de lo más significativo que expresan los jóvenes a través de cada año del proyecto.

En 2012, los jóvenes rescatan como significativos los momentos de reflexión generados a partir de las distintas excursiones al territorio que se plantearon como metodología para hacer más situada la formación de distintos conceptos. Por ejemplo, en el módulo donde se trató el manejo de residuos se acudió al vertedero municipal, que ninguno de los jóvenes conocía y fue muy impactante para ellos. Asimismo recuerdan los eventos comunitarios organizados, como por ejemplo el festejo por el día de la tierra, o la realización de una obra de teatro en la escuela primaria de la comunidad entre otros, ya que estos eventos les dieron una presencia comunitaria y un reconocimiento por parte de sus pares y de adultos. Ese año fue el que más participantes activos hubo en el colectivo, y cuando se desarrollaron los talleres educativos de manera más formal. Algunas de las palabras que los participantes asocian a la experiencia son: unión, felicidad, esperanza, oportunidad, amistad.

Durante el 2013 el colectivo Juxmapa continuó el proceso autogestionado, para entonces la vinculación con el Tribunal Permanente de los Pueblos, permitió a varios de los miembros del grupo viajar e interactuar con otras organizaciones del país. El monocultivo de maíz y la milpa fueron dos conceptos que quedan del proceso formativo, muy relacionados con la integración a la Red en Defensa del Maíz. Por lo anterior, los momentos más significativos que se rescatan de este año, son los viajes, el conocer otras experiencias organizativas, la presentación del caso de jóvenes rurales en el Tribunal, y una de las palabras que los participantes asocian a este año es "reconocer-me".

Durante el 2014, existen 3 momentos significativos recuperados de la reunión, la formación del grupo para niños/as en el Caracol, la realización de un taller llamado "Diagnóstico Ecológico Comunitario" que se realizó en la comunidad con miembros de otras organizaciones (en su mayoría adultos), y las audiencias finales del Tribunal 
Permanente de los Pueblos. En este año se asocian palabras como diversión y ayuda, relacionadas con el trabajo y con el grupo "compitas". La interacción generacional desde una diversidad de perspectivas es la seña particular de ese año.

Hacia el final de la reunión de sistematización, se pide a los participantes que expliquen con sus propias palabras $\mathrm{y}$ de forma libre el significado la experiencia. Se citan aquí algunos de sus relatos:

"Pues a mí se me hizo muy chido todo lo del Juxmapa, las subidas y las bajadas. A mí se me hacía como un proyecto diferente a lo que todos los días vemos, a la escuela, al catecismo. No sabía bien que era pero buscaba algo diferente, y como ya habíamos trabajado antes con otros proyectos del caracol y me gustaba pues entré...se me hizo bonito que éramos compañeros de diferentes niveles de la escuela, pues a mí me tocaba estar con quienes nunca nos habíamos hablado en la vida y eso era como chido. Era bonito estar conviviendo con gente de tu misma comunidad. Y eran muchas edades, se ponía como bueno el ambiente y conocías y aprendías de los demás; porque yo tenía la idea de que solo aprendías de los maestros, y yendo a la escuela, y ahí estaba saliendo como otra oportunidad de aprender entre nosotros mismos" (AJS, 2016, Reunión Sistematización).

"Yo siempre digo que si no hubiera estado en el colectivo no fuera igual que como soy ahorita, entonces siento que todas las experiencias que fuimos viviendo. Conocí lo que realmente era la milpa y lo que es el monocultivo, porque siempre uno crece con el mismo concepto de todo lo que te dicen ya sea en la escuela o lo que uno nada más escucha al ahí se va, como conocer lo que tienes y cómo mejorarlo. Además, en la etapa que lo viví, entonces yo era más chiquita, y siento que me ayudó mucho en mi madurez y a mi forma de desenvolverme". (NS, 2016, Reunión Sistematización).

"Los jóvenes nos tenemos que dar un tiempo para hablar de esto seriamente. Es un tema que ningún profesor te va a explicar. $\mathrm{La}$ educación que nos están dando está muy mal y tal parece que nadie se da cuenta" (JG, 2016, Reunión Sistematización).

"Yo pienso que, sí sería bueno involucrar más a los papás y a la demás gente, para que estén en el mismo rollo, para que entiendan por qué hacemos lo que hacemos" (MA, 2016, Reunión Sistematización).

Como se muestra en los relatos anteriores, los efectos en la vida de quienes participaron tiene muchos matices, sin embargo por las dimensiones del artículo, se abstraen de estos y otros testimonios, estos aprendizajes $y$ reflexiones principales del proyecto "Desde las raíces":

- La construcción de un espacio de socialización, desarrollo personal, diálogo, alegría y esperanza.

- Desarrollo de una mayor capacidad crítica ante decisiones y eventos cotidianos, por ejemplo, el consumo de alimentos y el uso de agrotóxicos.

- Convivencia y diálogo entre generaciones desde la horizontalidad 
- Replantearse su propio proyecto de vida y visión hacia el futuro.

- Comprender que hay otras formas de aprender.

- Necesidad de llevar y aportar lo vivido y aprendido durante el proceso a lugares $\mathrm{y}$ contextos distintos, en particular, con los adultos que los rodean.

\section{Reflexiones finales}

"El planeta no necesita más 'personas de éxito'. El planeta necesita desesperadamente más pacificadores, sanadores, restauradores, narradores de historias y amantes de todo tipo. Necesita que la gente viva bien en sus lugares. Necesita gente con coraje moral dispuestos a unirse a la lucha para hacer que el mundo sea habitable y humano."

Dalai Lama

El trayecto recorrido con "Desde las raíces" permite dar cuenta de que es posible proponer otras formas de trabajar y aprender con las niñeces y juventudes rurales. Que estas son capaces de autoorganizarse y construirse nuevos sentidos para la vida digna no solo personal sino comunitaria y en el campo, y apropiarse de su territorio y espacio. Si bien los más jóvenes, generalmente, son calificados generalmente como apáticos y poco participativos en el contexto de la educación escolarizada, esto no deja de ser una perspectiva adultocéntrica (Duarte, 2013); desde este proyecto es posible afirmar que cuando las juventudes son acompañadas con otros conocimientos más situados y más significativos, demuestran un alto nivel de motivación y acción.

Un acierto de esta experiencia educativa, es la integración de las diferentes perspectivas teóricas mencionadas, y en específico haber considerado las tres dimensiones que propone la condición juvenil rural. En la estructural se tuvo en cuenta el contexto de desarrollo agrícola hegemónico y sus efectos no solo ambientales sino en las relaciones sociales $\mathrm{y}$ en particular las intergeneracionales. En la territorial, se pudo ver como una conexión significativa con el lugar donde se vive, lleva a procesos de reterritorialización, niños, niños y jóvenes resignifican esos espacios que antes solo eran para los productores agrícolas y comienzan a involucrarse en las problemáticas que les afectan directamente, pero que no habían percibido por la educación formal. Mientras que la dimensión intersubjetiva es palpable al ver como el proceso educativo del proyecto genera nuevos sentidos para estas nuevas generaciones, en disputa con los sentidos de los adultos, fortalecidos con los procesos de organización, autogestión y participación comunitaria.

La experiencia vivida da cuenta de que del acto educativo se ha pasado a la 
socialización donde no solo se comparten saberes, ideas y sentires, y las formas de convivencia como comunidad, sino que estas se reinventan, se discuten y se reconstruyen, pero siempre teniendo en cuenta el territorio donde se encuentran los participantes localizados. Es este último el que da sentido a toda teoría y práctica.

Este aspecto es relevante, dado que para el equipo de profesionales que acompañó el proceso formativo del proyecto "Desde las raíces" y al "Colectivo Juxmapa", la acción comunitaria de este grupo de jóvenes, los invitó a volver a relacionarse con el territorio desde una proyección más política de su quehacer, en tanto, se asume la pertinencia no sólo de generar proyectos educativos para las juventudes rurales sino también de asumir la autogestión del proceso formativo y un rol de participación activa en la defensa del territorio. En ese sentido, esta experiencia buscó politizar la educación y pedagogizar la política (Torres, 2007) identificando rasgos distintivos de la educación popular como: la lectura crítica de la realidad, una opción ético-política emancipadora, la contribución a la transformación de los sectores populares en protagonistas del cambio social, la educación como formación de conciencia crítica y metodologías de trabajo basadas en la construcción colectiva del conocimiento.
Particularmente a nivel metodológico, otro desafío permanente fue mantener una vigilancia sobre las prácticas adultocentricas al interior del grupo de jóvenes y en la relación que se mantenía durante el acompañamiento con las y los jóvenes y las niñeces. Por otra parte, es imprescindible seguir generando experiencias pedagógicas desde los más pequeños, para poder plantear los problemas que forman parte de la crisis civilizatoria actual desde enfoques nuevos; de modo que sea posible inventar otras soluciones. El diálogo intergeneracional (Escobar C, 2020) es forzosamente un aspecto necesario para la generación de estas otras formas, como lo muestra el trabajo realizado. Asimismo, es urgente que los adultos se involucren más activamente en las acciones y discusiones abiertas por las juventudes.

Todo esto abre un sinfín de posibilidades para el trabajo concreto del Caracol Psicosocial, pues es necesario sembrar semillas fértiles que permitan la generación de nuevos futuros, pero también de nuevos presentes y no seguir esperando que sean las próximas generaciones las que cumplan la promesa de la defensa del territorio. 


\section{Referencias}

Ávila, R., \& Velázquez, A. (2006). Notas y reflexiones sobre los ranchos y rancheros. Una visión panorámica. Estudios del hombre, 81-100.

Barraza, L. (1998). Conservación y medio ambiente para niños menores de 5 años. Especies, 7(3), 19-23

Ceballos, Z., \& Tovar, S. (2010). Autogestión con jóvenes rurales: un camino para el desarrollo social y comunitario. Revista Investigium IRE Ciencias Sociales Y Humanas, 1(1), 134147. Recuperado a partir de https://investigiumire.unicesmag.edu.co/in dex.php/ire/article/view/12

Caracol Psicosocial. (2013). Transformándonos para el siguiente ciclo (2013-2015). Documento organizacional.

Caracol Psicosocial. (2016). Reunión de Sistematización. Documento organizacional.

Colectivo JUXMAPA. (2013). " $L a$ situación de las y los jóvenes de Palos Altos ante la destrucción de la vida campesina digna" Denuncia presentada ante la Audiencia temática del Tribunal Permanente de los Pueblos, "Violencia contra el maíz, la soberanía alimentaria y la autonomía de los pueblos". México, DF.

Duarte, K. (2013). Acción comunitaria con jóvenes. Desafíos Generacionales. Última Década, 169-195. https://doi.org/10.4067/S071822362013000200008

Durston, J. (2001). Juventud rural y desarrollo en América Latina. Estereotipos y realidades. En Burak, S. D. (Ed.). Adolescencia y juventud en América Latina (pp. 99-116). Cartago: Libro Universitario Regional (EULAC-GTZ).
Escobar, A. (2005). El "postdesarrollo" como concepto y práctica social. En Mato, D. (Ed.). Políticas de economía, ambiente y sociedad en tiempos de globalización (pp. 17-31). Caracas: Facultad de Ciencias económicas y sociales: Universidad Central de Venezuela.

Escobar, A. (2007). La invención del tercer mundo. Construcción y deconstrucción del desarrollo. Caracas: El perro y la rana.

Escobar C. L. (2020). Cuadernillo intergeneracionalidad. Oaxaca, México: IDEAS COMUNITARIAS.

Fernández Christlieb, P. (2001). El territorio instantáneo de la comunidad posmoderna. En Lindón, A. (Ed.). La vida cotidiana y su espacio-temporalidad (pp. 147-177). Barcelona: Anthropos.

Fernández Christlieb, P. (1994). La psicología colectiva un fin de siglo más tarde. Barcelona: Anthropos.

Freire, P. (1987). Pedagogía del Oprimido. México: Siglo XXI.

Giraldo, O., \& Toro, I. (2020). Afectividad ambiental: sensibilidad, empatía, estéticas del habitar. Chetumal: El Colegio de la Frontera Sur-Universidad Veracruzana.

GRAIN. (2014). ¡No toquen nuestro maíz! (el sistema agroalimentario industrial devasta y los pueblos en México resisten). Ciudad de México: Ithaca.

Gutiérrez-Rosete, J. G., (2011). Hacia una Pedagogía para la Integralidad (Tesis Doctoral ed.). Universidad La Salle Costa Rica - Universidad Veracruzana.

Kessler, G. (2007). Juventud rural en América latina. Panorama de las investigaciones actuales. En Bruniard, R. (Ed.). Educación, desarrollo rural y juventud (pp. 16-67). Buenos Aires: 
UNESCO - Secretaria de Agricultura, Ganaderia, pesca y alimentos.

Landini, F. (2009). Psicología en el ámbito rural, subjetividad campesina y estrategias de desarrollo (Tesis Doctoral). Universidad de Buenos Aires, Buenos Aires.

Landini, F. (2015). Hacia una psicología rural latinoamericana. Clacso.

Leff, E. (2004). Racionalidad Ambiental. Reapropiación social de la naturaleza. Siglo XXI Editores, México.

Maneja, R., Boada, M., \& Barrera-Bassols, N. (2009). Percepciones socioambientales infantiles y adolescentes: Propuestas de educación ambiental. La Huacana (Michoacán, México). Utopìa y Praxis Latinoamericana, 14(44), 39-51.

Martín-Baró, I. (1998). Psicología de la Liberación. Madrid: Trotta.

Mendoza, J. (2008) Tres malas palabras en psicología. Apuntes históricos y reflexiones sobre la práctica. Alternativas en Psicología, 13(18), 35-47.

Montero, M. (1984). La psicología comunitaria: Orígenes, principios $\mathrm{y}$ fundamentos teóricos. Revista Latinoamericana de Psicología, 16(3). 387-400.

Montero, M. (1980). La psicología social y el desarrollo de las comunidades en América Latina. Revista Latinoamericana de Psicología, 12(1), 159-170.

Montero, M. (2004). Introducción a la psicología comunitaria: Desarrollo, conceptos y procesos. Buenos Aires: Paidós.

Montero, M. (2004). Relaciones entre psicología social comunitaria, psicología crítica y psicología de la liberación: una respuesta latinoamericana. Psykhe, 13(2),
17-28. https://doi.org/10.4067/S0718$\underline{22282004000200002}$

Osorio, F. E. (2016). Juventudes rurales e identidades territoriales. En: Jóvenes, territorios y territorialidades. Bogotá: Pontificia Universidad Javeriana (pp. 1744).

Reguillo, R. (2010). La condición juvenil en el México contemporáneo: Biografías, incertidumbres y lugares. En Reguillo, R., \& Reguillo, R. (Eds.). Los jóvenes en México (pp. 395-429). México: FCE/Conaculta.

Sánchez, D. (2020). Palos Altos entre la muchachada y la juventud: la condición juvenil rural en una comunidad ranchera de Jalisco. Ciudad de México: Tesis doctoral. UAM Xochimilco.

Santos, B. (2009). La Epistemología del Sur Siglo XXI, México.

Svampa, M. (2019). Las fronteras del neoextractivismo en América Latina. Conflictos socioambientales, giro ecoterritorial y nuevas dependencias. Alemania: CALAS-Universidad de Guadalajara.

https://doi.org/10.14361/9783839445266

Torres, A. (2007). Paulo Freire y la Educación Popular. Recuperado de: https://www.dvv-

international.de/es/educacion-de-adultos-ydesarrollo/ediciones/ead-692007/eldecimo-aniversario-de-la-muerte-de-paulofreire/paulo-freire-y-la-educacion-popular

Urteaga, M. (2011). La construcción juvenil de la realidad. Jovenes mexicanos contemporaneos. México : UAM- I ; Juan Pablos Editor. 
i Tribunal de conciencia, heredero del tribunal Russel, que en su capítulo México, realizado de 2012 a 2014; recogió evidencias y casos que permitieron fundamentar la acusación hecha por toda la plataforma social del TPP. En resumen, se acusa al Estado Mexicano, instituido para procurar el bien común, de desviar su poder y beneficiar de manera sistemática a empresas transnacionales y capitales privados; generando con esto un ambiente de impunidad y violencia estructural contra el pueblo de México.

ii Tomado de la denuncia Ante el Tribunal Permanente de los Pueblos (GRAIN, 2014).

\section{Información del articulo / Article Information}

Recibido en: 31/03/2021

Aprobado en: 04/05/2021

Publicado en: $12 / 07 / 2021$

Received on March 31th, 2021

Accepted on May 04th, 2021

Published on July, 12th, 2021

Contribuciones en el artículo: David Sanchéz: Facilitador del proyecto. Reunión de sistematización para obtención de datos. Análisis de información y elaboración de marco teórico general. Patricio Meza-Opazo: Facilitador del proyecto. Reunión de sistematización para obtención de datos. Elaboración y revisión de marco teórico psicosocial. Claudia Águila-Robles: Integración de documentos, revisión de información, edición general de la información. Marco teórico educativo, y; aprobación de la versión final publicada.

Author Contributions: David Sanchéz: Project facilitator. Systematization meeting for data collection. Analysis of information and development of general theoretical framework. Patricio Meza-Opazo: Project facilitator. Systematization meeting for data collection. Elaboration and revision of the psychosocial theoretical framework. Claudia Águila-Robles: Integration of documents, review of information, general editing of information. Theoretical and educational framework, and; approval of the final published version.
Conflictos de Intereses: Los autores han declarado que no existe conflicto de intereses con respecto a este artículo.

Conflict of Interest: None reported.

\section{Evaluación del artículo}

Artículo evaluado por los revisores.

\section{Article Peer Review}

Double review.

\section{Agencia de financiación}

Consejo Nacional de Ciencia y Tecnología (México).

\section{Funding}

Consejo Nacional de Ciencia y Tecnología (México).

\section{Cómo citar este artículo / How to cite this article}

APA

Sanchéz-Sanchéz, D., Meza-Opazo, P. A., \& ÁguilaRobles, C. P. (2021). Reflexiones sobre una experiencia educativa para niñeces y juventudes rurales: el caso del proyecto "Desde las Raices" de Caracol Psicosocial A.C. Rev. Bras. Educ. Camp., 6, e11930. http://dx.doi.org/10.20873/uft.rbec.e11930

\section{ABNT}

SANCHÉZ-SANCHÉZ, D.; MEZA-OPAZO, P. A.; ÁGUILAROBLES, C. P. Reflexiones sobre una experiencia educativa para niñeces y juventudes rurales: el caso del proyecto "Desde las Raices" de Caracol Psicosocial A.C. Rev. Bras. Educ. Camp., Tocantinópolis, v. 6, e11930, 2021. http://dx.doi.org/10.20873/uft.rbec.e11930 